\title{
Motivations driving spiritual engagement based on a phenomenological study of spirituality amongst palliative care clients and caregivers
}

\author{
Joy Penman \\ Centre for Regional Engagement, University of South Australia, Australia
}

Correspondence: J oy Penman. Address: Centre for Regional Engagement, University of South Australia, 111 Nicolson Avenue, Whyalla Norrie, SA 5608, Australia. Telephone: 61-886-476-068. E-mail: joy.penman@unisa.edu.au

Received: December 22, 2011

Accepted: March 31, 2012

Published: August 1, 2012

DOI : 10.5430/jnep.v2n3p135

URL: http://dx.doi.org/10.5430/jnep.v2n3p135

\begin{abstract}
Objective: The attention given to spirituality has dramatically increased, especially in contemporary western society, because of its significant link to good health and well-being. Spirituality has relevance for individuals with life-limiting conditions. It is heightened when individuals encounter this predicament. The purpose of this research was to determine the essence of the lived experience of spirituality and spiritual engagement from the perspective of palliative care clients and caregivers. One of the objectives was to understand the reasons why they engage in spiritual matters and this is the focus of the paper.
\end{abstract}

Methods: A qualitative approach, based on van Manen's theoretical framework of hermeneutic phenomenology, was chosen for this research. This approach enabled human experience to be studied as it was lived and examined to the fullest breadth, depth and extent through a dynamic interplay of several research activities. In-depth interviews of four (4) palliative care clients and ten (10) caregivers from regional and rural Australia provided rich experiential discourse of what motivated them to engage in spiritual matters.

Results: The driving force that motivated the study participants to engage in spirituality was the benefits they might derive in the process of spiritual engagement. The motivations for spiritual engagement could be categorised as intrinsic and/or extrinsic. Intrinsic motivation, defined as the innate propensity to engage one's interest in spirituality and satisfy spiritual needs, included "to have peace and acceptance", "to seek healing”, "to be able to cope”, and "to find positive meaning in illness and suffering”. Extrinsic motivation, which comes from external influences and events that constitute the incentives and consequences to pursue spirituality, included "to communicate love and concern", "to better care for the loved one", "to build intimate relationships", and "to provide comfort to others". Once the drive or motivation arose, behavior was energised to engage in spiritual matters, reaping both self-serving and altruistic benefits.

Conclusions: Spirituality provided many real and potential benefits for those who engaged in it. Simply put, it helped participants cope. It becomes imperative for nurses and other health professionals to pay attention to these phenomena. The implications of this study relate to clinical practice and the educational preparation of nurses and other health professionals involved in caring for people with life-limiting conditions.

\section{Key words}

Spirituality, Spiritual engagement, Palliative care clients and caregivers 


\section{Introduction}

Spirituality has been defined in various ways including meaning-making, which has received wide support ${ }^{[1,2]}$. Currently, the conceptual understanding of spirituality has expanded to include connections amongst human beings, with nature and with their God ${ }^{[3,4]}$. This definition implies that, while spirituality is related to personal discovery and self-reflection, it also encompasses the ability to see beyond the self and become more than the physical person. Traditionally, spirituality has been linked with religion, but more contemporary views of spirituality are described as being humanistic and secular.

The experience of a life-limiting illness, defined as an incurable medical or surgical condition affecting any age group ${ }^{\text {[5] }}$, presents unique stresses for the individual involved and for their families. Confronting death for many individuals is a colossal challenge. Such challenge makes individuals thoroughly aware of their finiteness, limitation, loss of meaning and security ${ }^{[6,7]}$.

Spirituality has relevance for individuals with life-limiting conditions. It is heightened when individuals encounter this predicament. A possible explanation is that shortened life expectancy and uncertainty about the future spur individuals to re-examine their spirituality by reviewing their life and questioning its meaning ${ }^{[8]}$. Turning to spirituality is one way in which people find comfort and solace when confronted by dying and death.

In contemporary health care, individuals with life-limiting conditions are provided with palliative care, which is defined as an approach that improves the quality of life of patients facing life-threatening illness and their families through the prevention of suffering by comprehensive assessment and treatment of pain and other problems ${ }^{[9]}$. Palliative care is understood to be person-centred, dynamic, specialised and coordinated care. Through a multi-professional team, control of pain and other symptoms and management of physical, psychological, social and spiritual problems are achieved. The goal of palliative care is to provide the best quality of life possible for individuals and their families.

Spiritual care, defined as an aspect of professional behaviour assisting clients find meaning and purpose in their lives, maintain relationships and transcend a given moment ${ }^{[10]}$, is an essential component of palliative care. Research has shown that spirituality plays an important role in interpreting positively the illness ${ }^{[11]}$, better coping with illness, dying and death $^{[12]}$, deriving comfort and strength in facing the illness ${ }^{[13]}$, and increasing satisfaction in life despite a life-threatening condition ${ }^{[14]}$. Caregivers of dying clients who had a greater sense of spirituality and more social support had a significantly better quality of life predicted by their physical health status ${ }^{[15]}$. These outcomes rationalize why palliative care acknowledges the spiritual concerns of clients and significant others and endeavours to address these.

Unfortunately, addressing spiritual matters does not generally appear to be a priority in palliative care ${ }^{[16]}$. Spiritual care has often been limited to chaplains in hospices or spiritual counsellors, their traditional role ${ }^{\text {[17] }}$. However, this arrangement is now changing. With the acknowledgement of the centrality of spirituality in health and well-being, there is a move for other professional groups to engage in spiritual care ${ }^{[2]}$. The question is whether these professional groups are willing and ready to deal with spiritual matters.

The lack of emphasis on the spiritual in palliative care is due to many factors, including: time and institutional barriers, more precisely the current atmosphere of care provision with its emphasis on diagnostics and curative approaches ${ }^{[18]}$ and focus on physical pain and symptom control ${ }^{[19]}$; limited presence of chaplains in hospices or spiritual counsellors ${ }^{[20]}$; lack of information and training on spiritual beliefs and practices on the part of palliative care workers ${ }^{[21]}$; and patients themselves who do not wish to discuss spirituality issues for various reasons ${ }^{[22]}$.

This article reports on part of the findings of a larger research study on the multifaceted nature of spirituality and the many ways in which spirituality is manifested ${ }^{[23]}$. It highlights the value of engaging in spiritual matters and illuminates the intrinsic and extrinsic factors that motivate palliative care clients and caregivers in engaging with spiritual matters. This 
study can potentially enrich further the understanding of nurses and other health professionals on spirituality and enhance the spiritual experience of clients and caregivers as they face the reality of a life-limiting condition.

\section{Methods}

A qualitative approach was employed based on the theoretical framework of phenomenology. Specifically, a hermeneutic phenomenological human science approach was chosen. Inspired by van Manen ${ }^{[24]}$, this approach guided the study from start to finish, including methods, data gathering, analysis and writing. Developed and expounded by early philosophers such as Husserl, Heidegger, Merleau-Ponty and Gadamer, van Manen’s approach ${ }^{[24]}$ was deemed most appropriate.

\subsection{Design}

Van Manen's approach provided rich detail of the essence of people's spirituality and spiritual engagement experiences, including the motivations behind spiritual engagement. A dynamic interplay of several research activities took place, involving focusing on the lived experience, reflecting on the essential themes, and considering the parts and whole structures of the phenomenon ${ }^{[24,25]}$. The role of the researcher was to provide transparency of the research process and bring the readers as close as possible to the experiences and structures of the essences being perceived by the research participants.

\subsection{Participants}

The participants in the study were identified as being either a palliative care client or a caregiver. Clients consisted of individuals who had been diagnosed by their medical practitioner as suffering from a condition that at present has no cure, regardless of type of condition, stage of condition, gender, age or religious affiliation. Caregivers consisted of individuals who were providing care or had provided care to their loved ones diagnosed with a life-limiting condition. Caregivers could be spouses, partners, other family members and/or close friends.

Participants for selection in this study were required to have been diagnosed with a life-limiting condition or to have cared for a loved one with a life-limiting condition. The other criteria for inclusion were: over 18 years of age, able to speak English, and residing in regional and rural South Australia. Most potential participants were recruited through the palliative care teams of various hospitals and health services in the region. A few participants were recruited through personal invitation. Those who agreed to participate in the study were contacted and arrangements for the interviews were made.

All participants were given an introductory letter, which contained the purpose of the study and potential outcomes of the research. Also, the letter informed potential participants about the expected benefits of the research, the interview procedure, actual involvement requested of them, the voluntary nature of participation and assurance of confidentiality of information provided.

Twelve interviews were scheduled with potential participants. In two of these interviews, both palliative care client and caregiver were present and partners were invited to be interviewed; hence, a total of fourteen interviews were conducted. Of the fourteen who participated, ten were women and four were men. There were five Australian-born Caucasians, two non-Australian-born Caucasians, and seven Asian Australians from three different countries. The mean age of the group was 59, ages ranging from 34 to 77 years, and all from regional and rural South Australia. Of the fourteen interviewees, four were palliative care clients and ten were palliative care caregivers. Of the ten caregivers, four were currently caring for their loved one, while the remaining six were former carers. Nine reported that they belonged to the Catholic Church, while five said that they belonged to Protestant churches. While participants revealed that they had religious affiliations, not all were actively practising their professed religion. The primary diagnosis for the clients and the caregivers' loved ones was cancer. 


\subsection{Data collection}

Data collection in this study involved in-depth interviewing which was most appropriate because it allowed the exploration of the elements of spirituality and engaging in spirituality. In this method, participants were able to express their views, thoughts, attitudes, feelings and experiences about spirituality with greater clarity and depth. The interviews averaged 1.5 hours, ranging from 45 minutes to 2.5 hours in duration. Each interview was audio taped using a digital recorder and transcribed verbatim.

The researcher began by asking the client or the caregiver, "What is it like for you to experience a life-limiting condition?” or "What is/was it like for you to care for a loved one who has/had a life-limiting condition?" The initial question was followed with orienting questions, namely, "What was your experience of spirituality?" and "What was your experience of engaging in spiritual matters with your loved one?” This paper reports on the responses of participants to a focusing question, "Why do/did you engage in spiritual matters with your loved one?"

There was a potential emotional risk that might threaten participants' well-being as they narrated their experiences on dying, death and bereavement. However, this was not experienced during recruitment or interviews. Nevertheless, the following steps were to be undertaken should participants feel emotionally threatened: terminate the interview; demonstrate empathic understanding; allow the participant to express his/her feelings; offer to debrief or discuss the distress felt during the interview; and explore ways to assuage distress by contacting/referring to a counsellor, spiritual leader, social worker or palliative care specialist as appropriate.

\subsection{Data analysis}

The search for themes was accomplished through a series of analyses of the data. The transcripts were carefully examined and analysed using phenomenological reflection to grasp the essential meaning of spirituality and engaging in spiritual matters from the participant's description and understanding. The statements and phrases were reduced to codes and themes.

In determining the themes in a phenomenon in this study, two approaches were employed by this researcher: the "wholistic" and "selective" approaches as described by van Manen ${ }^{[24]}$. In the "wholistic" approach, the researcher examined the text as a whole and endeavoured to grasp its fundamental meaning. In the "selective" approach, the researcher read the text several times and asked what statements and phrases seemed particularly significant, and highlighted these to represent the themes of the experience being described. Data were coded by extracting verbatim phrases used by clients and caregivers to describe spirituality and spiritual engagement. Themes emerged from the data as recurring words and phrases or commonalities from among the codes developed.

\subsection{Ethical considerations}

Informed consent and permission to record data were obtained at the time of the initial interview with each participant. In order to preserve participants' anonymity and confidentiality, participants' names were not required at any stage of the research. Codes were used and access to data was limited to the researcher.

Permission to undertake the study was granted by the University's Human Research Ethics Committee (HREC). A protocol for the research was submitted to the HREC, according to the National Health and Medical Research Council (NHMRC) guidelines. Permission was sought also from various collaborating palliative care teams in the region.

\subsection{Trustworthiness and rigour}

Several strategies to ensure trustworthiness and rigour were employed. Trustworthiness, which reflects credibility, accuracy of representation, and authority of the researcher, were ensured by meeting Sandelowski's ${ }^{[25]}$ criteria for credibility, auditability, and objectivity. Credibility was established by matching the constructed realities of the researcher 
with those of the participants presented during interview and asking whether or not the findings were plausible, while auditability was ensured by presenting a clear and logical research procedure. Objectivity was achieved by examining personal preconceptions and presuppositions at the very start of the study, acknowledging and bringing them to the research experience.

\section{Findings}

In this research, impending death and death itself, bereavement, combined with heightened spirituality, constituted a life-changing event acting as a trigger for spiritual engagement. Spiritual engagement denotes the manner in which the research participants pursued and manifested their spirituality. The fundamental experience of engaging in spirituality for palliative care clients appeared to be no different from the experience of the caregivers. This means that they both interpreted spiritual engagement to mean 'relating and maintaining relationships' with others, with God or with themselves. The researcher believes that this is because of the closeness and intimacy in which these experiences were encountered by both the clients and caregivers.

\subsection{How spiritual issues are addressed}

The participants engaged in relationship-maintaining behaviours as a consequence of their spirituality. These behaviours were enduring and involved intimacy with others and with God. The ways the palliative care clients and caregivers engaged in spiritual matters were categorised as interpersonal, transpersonal and/or intrapersonal. These engagements may or may not be related to each other, and individuals may engage in one, two or all types of engagement. Figure 1 summarises the activities that clients and caregivers associated with engaging in spiritual matters. These activities will be explained.

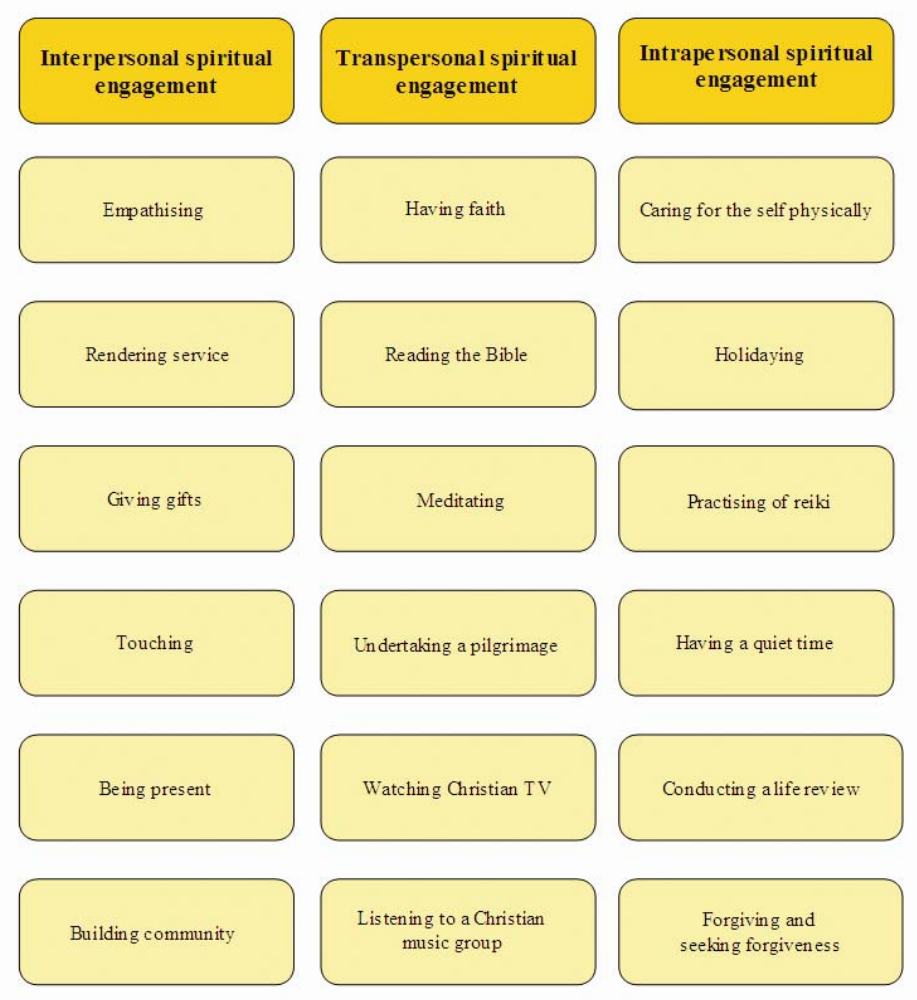

Figure 1. Manifestations of spiritual engagement 
"Interpersonal" spiritual engagement referred to the deep and meaningful connection between individuals (client and caregiver). The interpersonal spiritual engagement involved the intimate bonding between individuals and groups and manifested in various ways as acts of love. In this study, "transpersonal" spiritual engagement encompassed the vertical connection between the client and/or caregiver with God, higher being, nature or the universal power, while "intrapersonal" magnified the relationship of the client or caregiver with the self. The participants described these as connection with oneself, where spirituality provided the person's identity, character and meaning.

Turning to "empathising" in Figure 1, the participants were able to see the predicament through the eyes of the person for whom they were caring, which strengthened the bond between the client and caregiver. They (caregivers) responded by "rendering service" without any expectation of remuneration. Such services ranged from all sorts of mundane activities, from showering to pushing the wheelchair in the garden. "Giving gifts" was another activity the clients and caregivers indulged in because of the social and emotional meaning attached to it.

“Touching” was a means of communication employed by the participants to signify empathy and emotion. The act of touching gave specific messages, such as assuring that they were not alone and the desire to provide comfort and convey affection. Akin to touch was "being present" (also called "presencing"), which is physically and psychologically enjoying the presence of and connection with others. With "being there", the participants took opportunities to reminisce on past stories, experiences and events.

Spiritual engagement was like "being part of the community" and "building community", as depicted in Figure 1. Spiritual engagement was linked to the ties formed within the community, referring to the outstretched arms of caring community members, interacting closely, and commiserating with one another. Whether the community consisted of like-minded believers or of individuals from the same cultural and linguistic background, what was appreciated was the overt display of compassion and empathy that made the research participants feel special and loved, and part of the community. The church community, in particular, had been perceived as helping in addressing the physical, emotional and spiritual needs of its members, and church members were viewed as spiritual carers.

Accommodated also in Figure 1 are activities such as "having faith", "reading the Bible”, and "meditating” as ways by which transpersonal spiritual engagement was maintained. "Meditating" involved a broad variety of practices, ranging from techniques designed to promote relaxation to heightened sense of well-being. Palliative care client, Frederick, referred to Christian meditation as a form of prayer performed to connect with and deliberately reflect upon God's words, while other participants, such as Barbara, Ana, Hilary, Isabelle and Maria, considered meditation to mean focusing the attention on mental images, such as nature, universal power, having a healthy body, a painting or calming music. In so doing, they felt free from their predicament, even for a short while.

The clients and caregivers portrayed the ways in which they engaged intrapersonally by "holidaying" and "having a quiet time”. Holidaying for some resulted in having a break from their daily weary routines. Other participants made references to today's time-poor society and focused on having a quiet time, away from the "noise" and "busyness" of everyday life. "Quiet time" was referred to as a sacred and restful time devoted to loved ones. It also meant precious time for prayer, songs of praise, reading the Bible, and meditating. Indeed, quiet time meant just that - being still and quiet.

In addition, engaging in spiritual issues involved life review. This researcher likened the spiritual engagement activity to self-evaluation and life affirmation, where the palliative care clients endeavoured to declare that they had lived their lives to the fullest and were satisfied with their achievements and contributions, while the caregivers confirmed their declarations. The final spiritual engagement mentioned was letting go of resentments (forgiveness) and seeking forgiveness, as explained by participants Diana and Isabelle, embedded in Figure 1. As the participants would attest, forgiving others' shortcomings was beneficial in the long run because it gave them "peace of mind". 


\subsection{Motivations for engaging in spiritual matters}

In this study, the participants' motivations for spiritual engagement could be categorised as intrinsic and/or extrinsic. Intrinsic motivation is defined as the innate propensity to engage one's interest in spirituality and satisfy spiritual needs; extrinsic motivation comes from altruistic/philanthropic influences and events that constitute the incentives and consequences to pursue spirituality. Both types of motivations were observed from clients and caregivers. Figure 2 summarises the reasons why the participants engaged in spiritual matters.

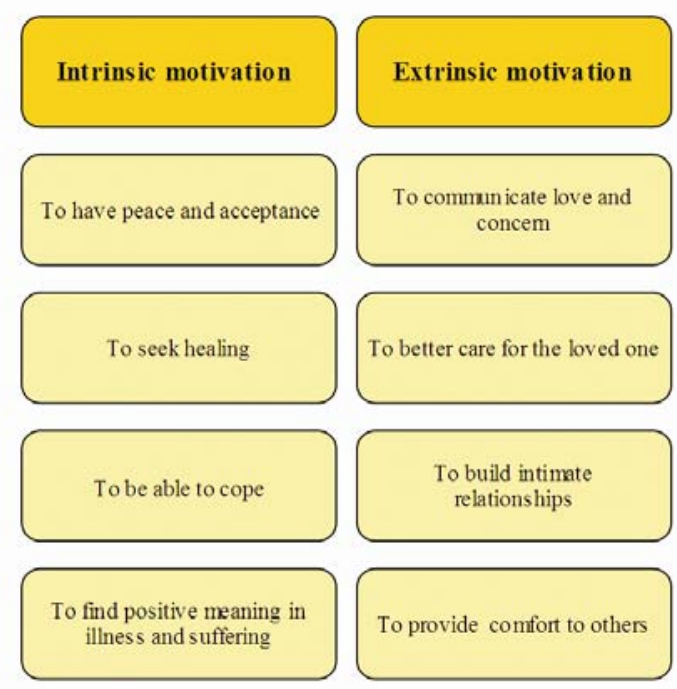

Figure 2. Motivations driving spiritual engagement

In considering the intrinsic motivation displayed in Figure 2, the palliative care clients and caregivers provided the following remarks to explain their motivations, which were directed toward helping themselves:

Barbara (client): Having a strong faith causes me to accept the fact that death is inevitable and that it is nothing to be afraid about.... My spiritual beliefs help me have peace and become more accepting of what is to come.

Nathan (client): ... I believe in reiki. Reiki is partly spiritual and it does work. ... Well, what we are doing it [reiki] for is mainly if I have a bit of pain or something like that. She [wife] gives me reiki and the pain goes away... It is good for healing and bonding too ...

Maria (caregiver): The power [from the universe] can be used for healing and peace and it is just as good for [my husband] as it is for me.

Frederick (client): My faith in God helps me cope. If you did not have faith, it will be very difficult... you will be unhappy because the illness will take you down all over the place... It takes the pressure off, removes fears about family, and makes life easy.

Hilary (caregiver): Engaging in spirituality helped me cope ... I did not feel so sad and abandoned....

Maria (caregiver): Prior to his illness, I never believed in complementary therapies ... but there is hope, finding a cure gave a positive meaning of the cancer ... 
The following excerpts exemplify the altruistic / philanthropic reasons for engaging in spiritual matters, as depicted in Figure 2.

Ana (caregiver): We prayed together because we believe that many prayers can make it lighter for her sickness, which was helpful for my niece.

Leah (caregiver): Engaging in spiritual issues was important in order as it was affirming our love for each other.

Jonathan (caregiver): My spiritual conviction helped me care for my ailing mother. ... My spiritual beliefs directed me to put her needs first, encouraging me to care for her.

Gina (caregiver): [Engaging in spiritual matters]... is about understanding perfectly each other's vulnerabilities, really seeing each other, and being there for each other no matter what may come.

Barbara (client): ... I was lucky I had friends that called in even when I was so sick ... someone would come here, sit down I'd make them a cup of coffee ... but more than the cups of tea and cakes, it was our way of connecting emotionally and spiritually which was providing comfort to everybody.

Frederick (client): ... We were supported very well. We derived strength and comfort from them [family, church and community members].

\subsection{Benefits of engaging in spiritual matters}

The study participants engaged in spirituality because of the benefits they might derive in the process of spiritual engagement. These benefits may be categorised as either self-serving or altruistic benefits. Examples of self-serving benefits from the clients' point of view included: "courage to persevere in life and resilience”, "reaffirm myself”, "reduce physical and emotional pain", and "remain positive and hopeful”. Examples of self-serving benefits from the caregivers' perspective were: "endure hardship", "care for the self”, "make sense of the situation”, and "strengthen coping”. Altruistic benefits for engaging in spirituality from the clients' responses included: "conquer fear and insecurities in family members" and "be able to love others"; while for the caregivers they included: "share the burden and alleviate suffering and pain”, "establish connections", "care for the loved one”, "achieve peaceful death”, and "have comfort and peace”.

The connection between the elements of the findings is represented in Figure 3. The figure shows that the motivation to engage in spiritual matters is driven by the need to help oneself and others, which leads to the manifestations of spirituality, which may be across several planes-interpersonal, transpersonal and/or intrapersonal. In the process of engaging in spiritual matters, benefits may be derived and these may be self-serving and/or altruistic.

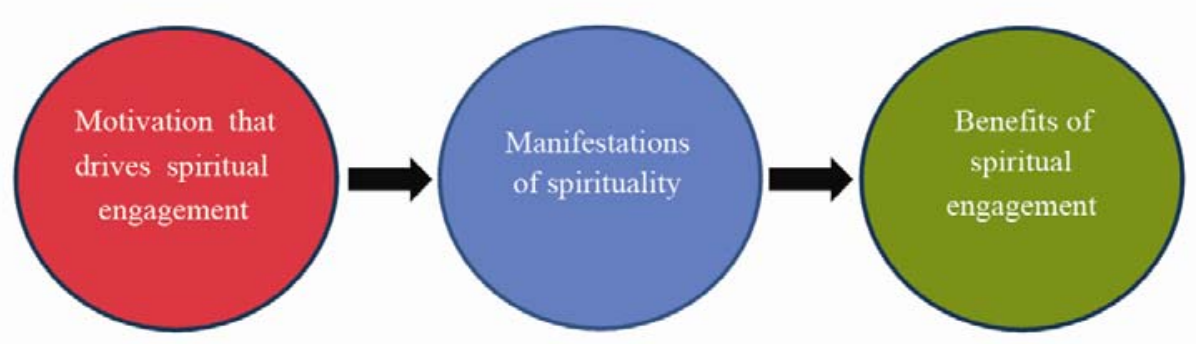

Figure 3. Connecting elements depicting spiritual engagement 


\section{Discussion}

Melding the stories of palliative care clients and caregivers has given rise to new meanings of understandings of what it was like for them to engage in spiritual matters and why. Through their experiences, the researcher has learnt that the human phenomena of spiritual engagement make individuals resilient. In the midst of being confronted with a life-limiting condition or impending death, associated pain, suffering and despair, the participants found ways and means to cope constructively and remain positive. It was evident that they drew strength from each other (client and caregiver) and lived from day to day hoping that the next day would bring an improvement in their situation. Such improvements were not necessarily associated with discovering a cure, but rather with reduced pain and suffering, a better frame of mind with less anxiety and depression, and generally being better able to cope with what was threatening them. In defiance of what was confronting them, these individuals continued to remain optimistic and even hopeful. The discussion examines some of the significant findings of the study that illuminate the lived experience of spiritual engagement of clients and caregivers as it relates to coping and good health and well-being.

\subsection{Spiritual engagement}

The participating palliative care clients and caregivers brought with them an awareness and capacity to articulate their spirituality. Utilising Reed's framework ${ }^{[27]}$, the interpersonal, transpersonal and intrapersonal spiritual engagement was elucidated. The spiritual manifestations were akin to those cited by MacKinlay ${ }^{[2]}$ including religion (worship, prayer, and reading of scriptures), through the arts (music, art, and dance), through the environment (nature, gardens), and relationships (intimacy with others and God). Additionally, finding sources of hope, strength, comfort, meaning, peace, love and connection were means of manifesting spirituality ${ }^{[28]}$.

The findings of this study are supported in literature. The value of human touch has been previously emphasised because a "caring touch" can help connect and break down barriers, and express concern and interest, decrease anxiety, diminish pain and create a bond between people ${ }^{[29]}$. With "being present", this researcher likens the spiritual engagement activity to self-evaluation and life affirmation. Story-telling and life review have been used in exploring spiritual issues ${ }^{[30]}$. Clients' telling their stories are attempts to reshape and give meaning to what is happening to them ${ }^{[31]}$. "Quiet time" is described as analogous to "being in a lived retreat" by Ohlen, Bengtsson, Skott and Segesten ${ }^{[32]}$ who wrote about a symbolic place owned by the individual which provides a feeling of being at home, where there is peace, rest, confidence, and breathing space in the person's suffering.

It was found that spirituality and spiritual engagement were related to patterns of beliefs and practices expressed by clients during the course of their illness. These patterns may signal to nurses the need to focus on the individual's self-concept and coping strategies because coping was found to be closely related to spirituality. Part of the spiritual care might be to accept the individual's belief system and pattern of behaviour resulting from the experience of coming to terms with dying. End-of-life spiritual care might be determined through the recognition of spirituality which nurses could identify and explore for the benefit of their clients.

The beneficial effects of engaging in spiritual matters have been highlighted in this study and other authors have supported this contention ${ }^{[33,34]}$. These opinions are significant because they help explain the impact of spirituality and the motivation behind palliative care clients and caregivers' engagement in spiritual matters. Of the many benefits of engaging in spiritual matters, increased coping and better physical and mental health and well-being are emphasised in the following section.

\subsection{Coping}

Coping is defined as "ongoing cognitive and behavioural efforts to manage specific external and/or internal demands that are appraised as taxing or exceeding the resources of the person" ${ }^{[35]}$. Of the two approaches to coping, the theory emphasising coping as a process is most relevant for this study. This theory views coping as change "over time and in 
accordance with the situational contexts in which it occurs" ${ }^{[35]}$. The measurement of coping is described in terms of the individual's thinking and doing in an attempt to cope with stress, such as impending death or death itself.

Individuals may employ a mixture of coping strategies - appraisal focused (adaptive cognitive), problem-focused (adaptive behavioural) and emotion focused - and may develop strategies that are adaptive or maladaptive ${ }^{[36]}$. Adaptive coping strategies employ constructive approaches to reduce the impact of the stress, while maladaptive strategies further compound the stress. The coping effort is dependent on the outcome, that relates to morale, social functioning, somatic health, personal meaning, emotional state and stress levels.

In this study, spiritual engagement served as a way of coping - physically, psychosocially and emotionally. The palliative care clients here were able to cope physically with the illness, pain, day-to-day challenges, and the process associated with dying through the aid of spirituality. On the other hand, the caregivers were able to cope psychosocially and emotionally with bereavement, grief and loss because of their spirituality. The participants' coping strategy (i.e. engaging in spiritual matters) was adaptive because they endeavoured to address the problem, find meaning in the experience, sought the support of others, drew strength from each other, and remained positive and hopeful. None of the participants exhibited self-blame, denial, or dissociation. Thus, spirituality proved to be an inner coping resource for these participants, a view supported also by other writers ${ }^{[37,38]}$.

\subsection{Good health and well-being}

Spirituality does matter. Spirituality has a bearing on positive physical health; studies on stress, cardiovascular conditions, pain, substance abuse and other medical conditions confirm the positive impact of spirituality on physical health. A case showing the influence of spirituality in managing pain is also documented. The positive impact of spirituality on pain relates to pain tolerance, headache frequency and mental and spiritual health. Spiritual meditation has been shown to decrease the frequency of migraine headaches and anxiety in individuals ${ }^{[39]}$. Moreover, the connections between spirituality and physical health in individuals with a chronic disability is another domain that is important to consider. Positive spiritual experiences gained from a willingness to forgive produces better physical health while negative spiritual experiences are shown to worsen physical and mental health in individuals with chronic disabilities ${ }^{[40]}$.

Being spiritual or having some spiritual beliefs can maintain and promote good mental health. The positive mental effects of spirituality encompass feelings of contentment and satisfaction, and less anxiety, depression and vulnerability ${ }^{[41]}$. An explanation as to why individuals with spiritual convictions are in better health is that their beliefs and practices give rise to creativity, patience, perseverance, honesty, kindness, compassion, hope and joy. In this study, giving meaning to the experience of dying and caring for their loved one helped some participants to evaluate the experience with positiveness and hope. Positiveness and hope were necessary to get them through the experience of death and bereavement. It was important for the clients and caregivers to deal with emotional and psychosocial issues in order to achieve positive self-evaluation. Positive self-evaluation would lead to enhanced mental well-being and this was possible because of spirituality. The role of spirituality in good mental health and well-being has been recounted ${ }^{[41,42]}$.

It should be acknowledged that unlike the findings of this study, other studies have reported that spirituality (as well as religious involvement) may have negative health outcomes. Spirituality does not guarantee good health and some religious beliefs can in fact be harmful ${ }^{[43]}$. For example, serious health implications may arise for an individual who substitutes prayer for medical care.

\section{I mplications of findings}

Two domains where the research findings might be applied were identified. These were in the areas of clinical practice for nurses and educational preparation of nurses and possibly other health professionals involved in caring for people with life-limiting conditions. Particular emphasis is given to nurses, mainly because this study was conducted by a nurse and 
nurses spend more time with palliative care clients, either within the confines of hospitals or in the community, than any other category of health professionals.

Nurses should respect their clients' spiritual beliefs and practices. In respecting them, they make things work for their clients, for example, providing a special time for reflection or a dedicated space for spiritual practices and opportunities to participate in religious activities such as praying and worshipping, holding conversations about the meaning of life and collaborating with chaplains and other religious leaders. Such activities aid spiritual engagement that assists nurses in authenticating their patients' experiences.

A profound finding of this study is that spirituality was integrated in relationships. Maintaining strong and oriented relationships were crucial features of spiritual engagement. It therefore requires nurses to be closely involved with their patients, to reach out on a personal level, build and maintain trusting relationships, in order to facilitate deep and meaningful connection with clients and facilitate spiritual engagement.

Education of nurses in this context refers to preparing nurses for accommodating spirituality in clinical practice; spirituality needs to be embedded in nursing curricula. Spirituality and spiritual engagement may be seamlessly integrated into the curricula and relatively easy to implement considering that holism underpins nursing education today. Spiritual engagement is a product of social interaction, not something to give, prescribe nor impose, rather it is a product of relationships and love; hence, this study endorses the inclusion of developing and sustaining client/caregiver-nurse spiritual relationship in the curriculum.

This researcher advocates contributing to the further refinement and development of concepts of spirituality within the Australian context and incorporating them into the nursing curriculum. The experiential perspective of the study participants may provide a trigger to discuss and focus on the human phenomena of spirituality and spiritual engagement.

\section{Conclusion}

The fundamental experience of spiritual engagement for both palliative care clients and caregivers was relating and maintaining relationships with others. This is the main essence highlighted in this study which brings home the overriding message that engaging in spiritual matters involved relationships and with that comes love, the love between family members and the love between people who share something in common. Those participants for whom relationships with others were significant in their understanding of spirituality engaged in spiritual matters by undertaking relationship-maintaining activities and actions.

This study is significant because it depicts the positive outcomes for coping with death and dying as a consequence of engaging in spiritual matters, contributing to the debate regarding the positive effect/s of spirituality on health and the role of relationships with others as a way of explaining the connection between spirituality and enhanced health status.

As spirituality provided many real and potential benefits for those who engaged in it, it becomes imperative for nurses and other health professionals caring for people with life-limiting conditions to use this resource in clinical practice. By demonstrating that they are considering the spiritual dimension nurses and other health professionals give a clear message that they are indeed concerned with the whole person ${ }^{[44]}$.

\section{References}

[1] Mitchell G, Murray J, Wilson P, Hutch R, Meredith P. Diagnosing and managing spiritual distress in palliative care: creating an intellectual framework for spirituality useable in clinical practice, AMJ. 2010; 3(6): 364-369.

http://dx.doi.org/10.4066/AMJ.2010.338 
[2] MacKinlay E. Spiritual care: recognising spiritual needs of older adults. In Aging, Spirituality and Palliative Care. E. MacKinlay, ed. Binghamton, New York: The Haworth Pastoral Press. 2006; 59-71.

[3] Wiklund L. Existential aspects of living with addiction - part II: caring needs. A hermeneutic expansion of qualitative findings. JCN. 2008; 17(18): 2435-2443. PMid:18705723 http://dx.doi.org/10.1111/j.1365-2702.2008.02357.x

[4] Harrington A. The 'connection' health care providers make with dying patients. In Aging, Spirituality and Palliative Care. E. MacKinlay, ed. Binghamton, New York: The Haworth Pastoral Press. 2006; 169-185.

[5] American Health Lawyers Association. A guide to legal issues in life-limiting conditions. Washington DC: Health Lawyers Public Information Series, 2005.

[6] Yang W, Hijmans E Staps T. Existential crisis and the awareness of dying: the role of meaning and spirituality. Omega: J Death Dying. 2010; 61(1): 53-69. http://dx.doi.org/10.2190/OM.61.1.c

[7] Efficace F, Marrone R. 'Spiritual issues quality of life assessment in cancer care', Death Stud. 2002: 26(9): 743-56. PMid:12385344 http://dx.doi.org/10.1080/07481180290106526

[8] Park CL. Estimated longevity and changes in spirituality in the context of advanced congestive heart failure. Palliat Support Care. 2008; 6(1):3-11. http://dx.doi.org/10.1017/S1478951508000023

[9] World Health Organization. WHO definition of palliative care [Internet]. 2011. Available from: http://www.who.int/cancer/palliative/definition/en/ (8 July 2011, date last accessed).

[10] Emblen JD. Religion and spirituality defined according to current use in nursing literature. J Prof Nurs. 1992; 8(1): 41-47. http://dx.doi.org/10.1016/8755-7223(92)90116-G

[11] Reed PG, Rousseau E. Spiritual inquiry and well-being in life-limiting illness. Journal of Religion, Spirituality and Aging. 2007; 19(4): 81-98. http://dx.doi.org/10.1300/J496v19n04_06

[12] Büssing A, Ostermann T, Matthiessen PF. Adaptive coping and spirituality as a resource in cancer patients. Breast Care. 2007; 2(4): 195-202. http://dx.doi.org/10.1159/000104172

[13] Albaugh JA. Spirituality and life-threatening illness: a phenomenologic study. Oncol Nurs Forum. 2003; 30(4): 593-598. PMid:12861320 http://dx.doi.org/10.1188/03.ONF.593-598

[14] Tsevat J, Sherman SN, McElwee JA, Mandell KL, Simbartl L, Sonnenberg FA, Fowler Jr FJ., The will to live among HIV-infected patients. Ann Intern Med. 1999; 131(3): 194-198. PMid:10428736

[15] Tang W-R. Hospice family caregivers’ quality of life. J Clin Nurs. 2009; 18(18): 2563-2572. PMid:19538564 http://dx.doi.org/10.1111/j.1365-2702.2008.02753.x

[16] Miller DK, Chibnall JT, Videen SD, Duckro PN. Supportive-affective group experience for persons with life-threatening illness: reducing spiritual, psychological, and death-related distress in dying patients. J Palliat Med. 2005; 8(2): 333-343. PMid:15890044 http://dx.doi.org/10.1089/jpm.2005.8.333

[17] Irons L. Ear for Stories. Insights Magazine [Internet]. 2006. Available from: http://insights.uca.org.au/2005/december/chaplains-conference-2005.htm (6 October 2008, date last accessed).

[18] Kaut KP. Religion, spirituality, and existentialism near the end of life: implications for assessment and application. Am Behav Sci. 2002; 46(2): 220-234. http://dx.doi.org/10.1177/000276402236675

[19] Steinhauser KE, Alexander SC, Byock IR, George LK, Olsen MK, Tulsky JA. Do preparation and life completion discussions improve functioning and quality of life in seriously ill patients? Pilot randomized control trial. J Palliat Med. 2008; 11(9): 1234-1240. PMid:19021487 http://dx.doi.org/10.1089/jpm.2008.0078

[20] Brumley RD, Hillary K. The tricentral palliative care program toolkit [Internet]. 2002. Available from: http://www.mywhatever.com/cifwriter/content/22/files/sorostollkitfinal120902.doc (11 March 2007, date last accessed).

[21] Woll ML, Hinshaw DB, Pawlik, TM. Spirituality and religion in the care of surgical oncology patients with life-threatening or advanced illnesses. Ann Surg Oncol. 2008; 15(11): 3048-3057. PMid:18773242 http://dx.doi.org/10.1245/s10434-008-0130-9

[22] King DE, Bushwick B. Beliefs and attitudes of hospital inpatients about faith healing and prayer. J Fam Pract. 1994; 39: 349-352. PMid:7931113

[23] Penman J, Oliver M, Harrington A. Spirituality and spiritual engagement as perceived by palliative care clients and caregivers. Aust J Adv Nurs. 2009; 26(4): 29-35.

[24] van Manen M. Researching lived experience: human science for an action sensitive pedagogy. 2nd edn. Ontario: The Althouse Press; 1997.

[25] Munhall P. A phenomenological method. In Nursing research: A qualitative perspective. P Munhall, ed. Sudbury, MA: Jones \& Bartlett Publishers. 2007; 145-210.

[26] Sandelowski M. Rigor or rigor mortis: the problem of rigor in qualitative research revisited. Adv Nurs Sci. 1993; 16(2): 1-8.

[27] Reed PG. An emerging paradigm for the investigation of spirituality in nursing. Res Nurs Health. 1992; 15: $349-357$. http://dx.doi.org/10.1002/nur.4770150505 
[28] Anandarajah G, Hight E. Spirituality and medical practice: using the HOPE questions as a practical tool for spiritual assessment. Am Fam Physician. 2001; 63(1): 81-89. PMid:11195773

[29] Ludwig-Beymer P. Transcultural aspects of pain. In Transcultural Concepts in Nursing Care. 4th edn. MM Andrews and JS Boyle, ed. Philadelphia: Lippincott Williams \& Wilkins. 2003; 405-431.

[30] Larocca-Pitts MA. FACT: Taking a spiritual history in a clinical setting. J Health Care Chaplain. 2008 ; $15(1)$ : 1-12. PMid:19424909 http://dx.doi.org/10.1080/08854720802698350

[31] Shaw R. Healing through story. In 9th Asia Pacific Hospice Conference: 14-17 July; Penang, Malaysia. $2011 ; 70$.

[32] Ohlen J, Bengtsson J, Skott C, Segesten, K. Being in a lived retreat--embodied meaning of alleviated suffering. Cancer Nurs. 2002; 25(4): 318-25. http://dx.doi.org/10.1097/00002820-200208000-00008

[33] Mystakidou K, Tsilika E, Prapa E, Smyrnioti M, Pagoropoulou A, Lambros V. Predictors of spirituality at the end of life. Can Fam Phys. 2008; 54(12): 1720-1721+1721.e1-1721.e5.

[34] Mueller, PS, Plevak, DJ \& Rummans, TA. Religious involvement, spirituality, and medicine: implications for clinical practice. MAYO Clin Proc. 2001; 76(12): 1225-35. PMid:11761504 http://dx.doi.org/10.4065/76.12.1225

[35] Lazarus RS. Coping theory and research: past, present, and future. Psychosom Med. 1993; 55: 234-247.

[36] Weiten W, Lloyd MA. Psychology Applied to Modern Life. 9th edn. Wadsworth Cengage Learning, 2008.

[37] Wink P. Who is afraid of death? Religiousness, spirituality and death anxiety in late adulthood. In Aging, Spirituality and Palliative Care. E MacKinlay, ed. Binghamton, New York: The Haworth Pastoral Press. 2006; 93-110.

[38] Baldacchino D, Draper P. Spiritual coping strategies: a review of the nursing research literature, J Adv Nurs. 2001; 34(6): 833-841. PMid:11422554 http://dx.doi.org/10.1046/j.1365-2648.2001.01814.x

[39] Wachholtz, AB, Pargament, KI. Migraines and meditation: does spirituality matter? J Behav Med. 2008; 31(4): 351-366. PMid:18551362 http://dx.doi.org/10.1007/s10865-008-9159-2

[40] Johnston B, Yoon DP. Relationships between the brief multidimensional measure of religiousness/spirituality and health outcomes for a heterogeneous rehabilitation population. Rehabil Psychol. 2009; 54(4): 422-431. PMid:19929124

http://dx.doi.org/10.1037/a0017758

[41] Chaudhry HR. Psychiatric care in Asia: spirituality and religious connotations. Int Rev of Psychiatr. 2008; $20(5): 477-483$. PMid:19012134 http://dx.doi.org/10.1080/09540260802397602

[42] Yi MS, Luckhaupt SE, Mrus JM, Mueller CV, Peterman AH, Puchalski CM, Tsevat, J. Religion, spirituality, and depressive symptoms in primary care houseofficers', Ambul Pediatr. 2006; 6(2): 84-90. PMid:16530144 http://dx.doi.org/10.1016/j.ambp.2005.10.002

[43] University of Maryland Medical Center. Spirituality [Internet]. Available from: http://www.umm.edu/altmed/articles/spirituality-000360.htm (13 December 2011, date last accessed)

[44] D’Souza R. The importance of spirituality in medicine and its application to clinical practice. MJA. 2007; $186(10$ Suppl): S57-59. PMid:17516886 